\section{Being Enzo}

$\mathrm{M}$ edical students don't become doctors on graduation day. They graduate July 1 , alone on the wards, a baptism by fire.

Last night was my fourth night on call as a resident doctor. Two weeks in, I'm still a newbie, a fledgling, a bona fide greener. Sometimes I feel competent and capable, walking around as if I own the place, my white coat flowing behind me like a kingly robe. But then night falls, and I'm alone, and uncertain, and afraid. I'm afraid my patients in the cardiac care unit won't do well, and that I'll be left wondering whether I could have saved them had I done something differently. I make decisions out of necessity, and then worry about whether my casual, "Yes it's fine, give them the medication," will be the downfall of some poor soul unfortunate enough to end up in my ward.

Yesterday afternoon, a 69-year-old man of Scottish origin arrived from his nursing home to the emergency department with worsening shortness of breath. He was already a very sick man, unable to walk for the past five months because of chronic ulcers on his feet. He had a history of heart failure, so we started him on high-dose diuretics, hoping they would help his difficulty breathing. And then my attending left. On call for the night, I alone would look after my patients.

The Scottish patient (for that is what I must call Mr. Macbeth) looked unwell. I had come to re-evaluate him, but I was distracted by the tiny TV in his room. "The Godfather" was on. It was the scene where Michael Corleone rushes to the hospital in the middle of the night to the bedside of his sick father, Vito, laid low by an attempt on his life by rival gangsters, only to find that his father's bodyguards and police escorts have abandoned him. He runs into Enzo, the friendly baker, who has brought Vito a bouquet of flowers, and

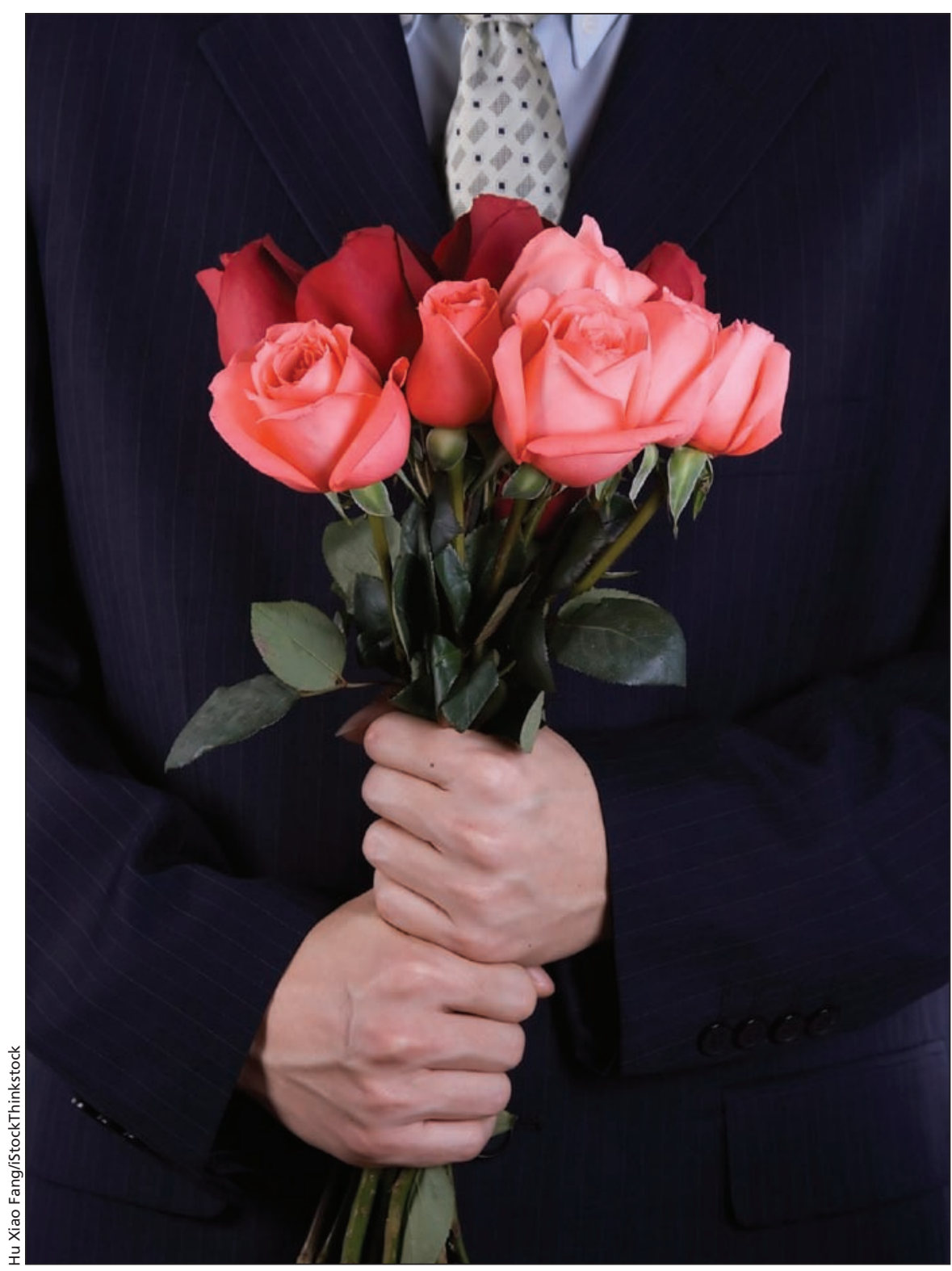

asks Enzo to stand guard with him outside the hospital. Without a weapon between them, the two must keep the Don safe until reinforcements arrive to protect him from a second hit.

My poor patient was unaware of the cinematic exhibition. He was gasping for breath, despite having good oxygen saturation. "Och, doctor," he said between gasps. "I'm having seu much trouble catchin' me breath." I told him we were doing the best we could to help him. "I thank ye fer yer help, doctor, but sometimes I think it'd be better if I would just die."

I told him I knew how he felt, even though I didn't. I told him it would be alright, even though I didn't know if it 
would. To be bedridden and confined to a nursing home, with no family for miles, at the age of $69 \ldots$ I offered him platitudes rather than crying by his bedside over his fate.

Though I had plenty of other patients to worry about, I spent most of my time and most of my worry worrying about my Scottish patient. I learned that his potassium was high and agonized over his ECG for signs of hyperkalemia. I learned that his troponins

one in my patient's left hand would likely explode. I begged the nurse to tell the CT technician to infuse the contrast slowly, so that maybe the vein wouldn't blow. She looked at me like I was crazy.

I paced around my patient's bed, willing him back to health. "Doctor, I can't do it much longer. I'm still seu short o' breath. I'm scared, Doc.' I told him I was so sorry on behalf of the universe. We were going to keep doing our

\section{I told him I knew how he felt, even though I didn't. I told him it would be alright, even though I didn't know if it would.}

were high, with nonspecific changes on his ECG. After conferring with my attending by phone, I started him on the acute coronary syndrome protocol for a possible heart attack. Then, my patient told me he was having sharp chest pain with every breath. "And could ye bring me the bin? I need to spit up." He hocked a blood-stained wad into a napkin.

Again, I hesitated. I knew full well that what I saw and heard was typical of a pulmonary embolus, but after four long years of being a medical student, I was conditioned to ask instead of tell. I ordered the requisite chest $\mathrm{CT}$, but only after a well-deserved "Duh" from my attending.

All night, my Scottish patient's body refused to let me relax. His extremities became cold, even though his blood pressure was fine. His veins allowed entrance to only one tiny IV, and try as they might, the nurses were unable to get another one in. It took them forever to get enough blood to send for a repeat potassium.

My heart would not stop racing for fear that his would grind to a halt. To rule out a pulmonary embolus, the chest CT would need contrast infused through a large-gauge needle; the tiny best to help him. "Och, I'm such a bother. What's the use?" I shook my head, trying not to cry, and told him to keep bothering me, that it was no bother at all, that we were all here to help him. "I can't even work up the energy to call m'brother in Vancouver," he said, speaking so softly that I had to lean in to hear him. "He's got his own problems ..." Now it was my patient's turn to fight back tears, his eyes huge and bulbous through his thick prescription lenses. I nodded sympathetically and could only hold his hand for a few seconds before I had to flee from the room to pace elsewhere.

"If only I can keep him alive until morning," I thought to myself. I knew that if I could stave off the forces of darkness for a few hours longer, the day team would arrive, and we would save his life together. "Please don't let him die tonight," I pleaded into the void.

The radiology resident called to say that he had found no evidence of pulmonary embolus, but that he saw what looked like multifocal pneumonia. Again, I texted my attending with questions to which I already knew the answers. Should I order blood cultures and start IV antibiotics? Of course I should. Why did I keep waking her up just for my own peace of mind? I asked for blood cultures (which, with the patient's terrible veins, couldn't be done anyway) and started him on IV antibiotics. I sighed with relief for the first time that night.

Michael Corleone and Enzo the baker stand outside on the stoop. Michael snatches the bouquet of flowers from Enzo, tosses it away and hikes up Enzo's collar so that he looks more intimidating. "Put your hand in your pocket like you have a gun. You'll be alright." Enzo nervously puts his hand in his pocket. They watch the street. A black sedan pulls up in front of the hospital, and the mobsters inside look at the pair on the stoop. Michael unbuttons his jacket as if he's reaching for his gun. The guys in the car look away and the car drives off.

"You did good," says Michael. Enzo is scared and pale, trembling as he pulls out a cigarette and a lighter. He is shaking so hard that he can't light his cigarette. Michael helps him light it as police cars pull up, sirens blazing. They did it. They saved Don Corleone.

Michael is a hero. He is cool under pressure, knows what needs to be done, and in the middle of the night, when he has nothing but his own guile to rely on, he gets it done. Enzo, on the other hand, is in the right place at the right time. Maybe he knows what to do and maybe he doesn't, but boy can he follow directions.

I am not Michael Corleone. One day I will be, I really will be. But last night, I was Enzo the baker. And I saved the Scottish Don, in my own way.

\section{Ariel Lefkowitz MD CM \\ Department of Internal Medicine \\ University of Toronto \\ Toronto, Ont.}

This is a true story. The patient's substitute decision-maker has given consent for this story to be told.

CMAJ 2014. DOI:10.1503/cmaj.140227 